\title{
COVID-19: Optimizing Business Performance through Agile Business Intelligence and Data Analytics
}

\author{
Andy Ohemeng Asare', Prince Clement Addo², Eric Ohemeng Sarpong², Daniel Kotei² \\ ${ }^{1}$ George Brown College, Centre for Business, Ontario, Canada \\ ${ }^{2}$ University of Electronic Science and Technology of China, School of Management and Economics, Chengdu, China \\ Email: andyohemengasare@yahoo.com
}

How to cite this paper: Asare, A. O., Addo, P. C., Sarpong, E. O., \& Kotei, D. (2020). COVID-19: Optimizing Business Performance through Agile Business Intelligence and Data Analytics. Open Journal of Business and Management, 8, 2071-2080. https://doi.org/10.4236/ojbm.2020.85126

Received: July 19, 2020

Accepted: August 31, 2020

Published: September 3, 2020

Copyright $\odot 2020$ by author(s) and Scientific Research Publishing Inc. This work is licensed under the Creative Commons Attribution International License (CC BY 4.0).

http://creativecommons.org/licenses/by/4.0/

\begin{abstract}
The current COVID-19 pandemic has led to a devastating socio-economic predicament, which has resulted in the temporary closure and collapse of thousands of businesses across the globe. The quicker companies can respond to the current pandemic situation, the more likely their chances of surviving in the short or long term. Businesses around the world are compelled to make significant changes to their business operations, such as downsizing, product, and service diversification. To address these changes quickly, companies need to adopt or capitalize on their business intelligence strategies through agile risk management, artificial intelligence systems, and data analytics to help make informed decisions to enhance business operations amid COVID-19. This article outlines some practical and theoretical recommendations of business intelligence strategies for organizations and their service supply chain network on how to be adaptive, flexible, and innovative to survive and stay competitive during these challenging times by leveraging agile dimensions, artificial intelligence systems, and data analytics.
\end{abstract}

\section{Keywords}

COVID-19, Service Supply Chain Network, Agile Business Intelligence, Artificial Intelligence, Data Analytics

\section{Introduction}

COVID-19 is one of the deadliest viruses ever to have affected the world. Since the spread of the virus, most essential and non-essential businesses have had no choice than to lose stock market price, downsize, close temporary, and fold their 
arms awaiting government interventions or risk a complete collapse of their business. A recent post in the Calgary Herald (Hudes, 2020) revealed that due to COVID-19, one-third of businesses fear they will permanently close within a month. The article further mentioned that nearly 10,000 small business owners in Canada indicated that around one in three feel they will not survive longer than a month under the current economic conditions.

Most businesses have already received their lion's share of the devastating effects of the novel virus on their business finances. This corresponds to a joint study by the World Economic Forum and United Nations, which indicated that the slowdown in the global economy caused by the novel virus is expected to cost at least \$1 trillion (World Economic Forum, 2020).

Evidently, COVID-19 is a global economic situation that most businesses across the globe must sail through or see their boat capsizing through the oceans. Although most companies have a flexible and agile business model to adapt to changes and uncertainties, that is not the case for other businesses, particularly small and medium enterprises.

COVID-19 is the game-changer that is leading to unprecedented changes and transformation of businesses across the globe by requiring new operational, production, and service processes. The service supply chain industry is one of the essential industries sustaining most economies during these trying times through high job demand, materials procurement, production, warehousing of goods, inventory control, distribution, and the delivery of essential products and services. While the US-Canada borders were closed for non-essential movements, businesses within the supply chain industry were among the few essential enterprises.

To maintain smooth business operations, there is the need for management to strategically manage the activities within their firm and service supply chain networks using agility strategies, artificial intelligence, and data analytics capabilities to sustain their business and meet the uncertain demands during these challenging times.

Agile Business Intelligence in this study defines the ability of a firm to create and respond to changes within its business environment through agile risk management strategies, artificial intelligence (AI) technologies, and data analytics capabilities for data gathering, interpreting, and communicating meaningful patterns, the data to help management make effective business decisions and take action.

In this study, the application of artificial intelligence and analytic processes is fused with the various agility risk management components: consciousness, availability, decisiveness, speed, and flexibility within the supply chain network. The fact can never be disputed that the effective use of artificial intelligence systems and data analytics capabilities within the agile dimension's components will help improve and sustain an organization and its service supply chain network as we go through unprecedented dynamic times. This is because the service 
supply chain network is made up of companies that are distinct from each other. However, they strongly rely on each other through information flow, capacity and skills management, demand and supply, customer engagement, service delivery, and cash flow for most business activities (Baltacioglu et al., 2007; Ellram et al., 2004).

The application of AI and data analytics-driven by systems that use "intelligent agents," complex algorithms such as machine learning, Natural Language Processing (NLP), and robotics enable managers to gain insight into business information, perform tasks, and adapt to industry changes (Blume Global, 2020).

Considerably, the current changes as a result of the novel COVID-19 call for a revisit of agility risk management dimensions through the integration of artificial intelligence systems and data analytics to help managers gain insights within their internal and external organization to make effective decisions to take necessary actions, particularly with flexibility and responsiveness to enhance business performance.

Most service supply chain networks' scholarly works on agility have focused mainly on enriching a firm's internal and external agility processes. However, with less emphasis on the effective use of artificial intelligence systems, and data analytics capabilities, for the adaptability, responsiveness, and flexibility of businesses during crisis.

To bridge these gaps, this article outlines some agile business intelligence strategies to improve an organization's internal processes and service supply chain networks, through agility dimensions, artificial intelligence, and data analytics capabilities, during and after the COVID-19 crisis. The rest of the paper is organized as follows. The next section delves into the effective use of agility dimensions, artificial intelligence, data analytics capabilities, and administrative strategies for the survival of businesses during these pandemic times. We then present practical research implications, which include practical, and theoretical implications with research limitations. The final section concludes with a summary of the study.

\section{Agility Dimensions, Artificial Intelligence and Data Analytics Capabilities}

\subsection{Consciousness: Did You See This COVID-19 Coming?}

Consciousness is the ability of a business to quickly predict changes, opportunities, and threats within its business arena. Thus, awareness requires knowledge of sensitivity, uncertainties, changes, and compatibility within a business environment. The role of consciousness in achieving the desired level of business intelligence to help decision making in this study is emphasized on the deployment of artificial intelligence systems and analytics. This requires strong coordination, easy access, and information flow within a firm and its various service supply chain networks, using artificial intelligence systems such as Natural Language Process (NLP), Birst Supply Chain Analytics, and SAS Supply Chain Intel- 
ligence to integrate data from various network sources in real-time. These systems can also be used to gather data from stakeholders to gain insight into current market demand patterns, supply networks, operations, and customer service requirements, (Imanuel, 2014; Fruhlinger, 2019; Pontius, 2020).

Using descriptive analytics, managers within the service supply chain network can gather historical and current market data for further analysis through data aggregation and mining methods to identify patterns and relationships in data. More insights may be yielded through data queries, reports, and visualization. At this stage, it is recommended that management perform diagnostic analytics to gain an in-depth understanding of the data gathered to understand the causes of events and behaviors. This will help management predict uncertainties and determine the demand and supply for goods and services during and after the COVID-19 pandemic.

\subsection{Accessibility: Is Your Data Available?}

Accessibility defines the ability of an organization and its supply chain network to quickly access relevant data and information after using its conscious capabilities to detect changes to enable managers to make informed decisions regarding changes in their business environment.

Access to data and information in real-time is a crucial requirement and determinant for an organization's agility in dealing with uncertainties. During these unprecedented times, it is highly recommended that organizations and their service supply chain networks make data available on-demand and easily accessible across the various levels of the firm and within their network for a swift and instant response to market changes. Available data might include information on demand and supply, capacity and skills management, inventory control, production, delivery, customer relationship, cash flow, and government requirements. The integration of information and data plays a vital role in an organization's agile strategies to collect and disseminate accurate information.

Although this process can sometimes be challenging due to the enormous amount of data available with an organization, the practical application of artificial intelligence systems such as PeopleSoft, JDA Supply Chain Analytics, SAS Supply Chain Intelligence, Microsoft Power BI, Tableau and Manhattan Associate visibility and insights makes the dissemination of data and information across organizations much more viable, (Fruhlinger, 2019; Imanuel, 2014; Pontius, 2020).

By applying business intelligence systems and predictive analytics, management will gain insights from data and information shared across the organization and its service supply chain networks to predict the most likely outcomes or future scenarios and its implications on business operations. This will enable organizations and their service supply chain networks to identify, plan and mitigate any disruption or risk in the supply of raw materials, availability of labor force, manufacturing process, government regulations, warehousing and lo- 
gistics, and other stakeholders' issue during this COVID-19 season.

\subsection{Decisiveness: What Are You Waiting for?}

This agility dimension defines management's ability to make a firm and resolute decision based on reports and insights gained from the data and information gathered in responding to market changes. Decision-making at the management level can sometimes be challenging due to the increasing size of the supply chain network, an organizational structure, escalation of decisions, decision making time, and high level of bureaucracy, (de Smet, 2017; Meehan \& Colette Seidel, 2019). In the long run, managers that can make swift decisions are better able to lead their organization to detect threats and or seize market opportunities. Through the application of prescriptive analytics, businesses will be better positioned to eliminate all hurdles in the decision-making process within their organization and service supply chain networks through problem-solving and collaboration in mitigating disruptions and risk. Employing supply chain artificial intelligence systems embedded with machine learning will enable businesses to move from a reactive mode to a more proactive position by monitoring, controlling, and measuring service supply chain events. Using this software will also provide predictive real-time insight into business opportunities, priorities, and challenges in meeting the demand of stakeholders.

\subsection{Speed: Move Quick}

Speed in the agility dimensions defines how quickly or swiftly an organization can implement decision or act. This follows in sequence after a decision has been made on how to respond to market changes and any uncertainties. The ability to act swiftly by businesses is very utmost during these challenging times to meet the tremendous disruptions.

During the COVID-19 period, we have witnessed many businesses that have switched from producing their traditional products and service to provide goods and services that are of high demand, especially personal protective equipment (PPE) and hygiene products. Foxconn, one of the world's electronic giants and the maker of most Apple products, has switched part of its production to produce surgical marks, promising to produce 2 million masks per day (BBC, 2020). Automobile companies such as Ford have swiftly switched to providing medical supplies by assembling more than 100,000 plastic face shields per week (Mich, 2020; Trieu, 2020).

Using artificial intelligence systems offers cognitive analytics or analytical depth and speed response for both organizational planning and response cycle. Managers will then be able to ask and answer complex questions in natural language processing (NLP) to optimize their operations during this period.

\subsection{Flexibility: Do You Want to Keep the Same Tactics?}

Flexibility defines an organization's ability to modify its range of service supply 
chain tactics and operations to successfully implement its agility strategies instead of living in maxim. Organizations should consistently try new methods and processes that work efficiently and effectively to promote innovation rather than being comfortable and reliant on old ways of doing things.

The use of artificial intelligence tools enables managers to manage business processes on a priority basis, be more proactive with predictive analytics, benchmark against current industry standards, and practice using data. AI systems also enable firms to conduct cognitive analytics in their planning process and response cycle to better produce essential and transformable products and services during and after the COVI9-19 pandemic.

\section{Administrative Strategies}

\subsection{Perceive the Current On-Going Challenges as New Opportunities Rather than Threats}

Business challenges are inevitable; however, out of these challenges are opportunities. Although new challenges come with fear and uncertainties, avoiding these challenges limits your opportunities to learn more about your business environment. Out of COVID-19, some restaurants are now converting their space to sell groceries and staple items to stay afloat, auto dealerships and related businesses are embracing the home delivery model, Foxconn is producing thousands of face marks, General Motors, Ford, and Tesla are making ventilators, (BBC, 2020; Desai, 2020; Gorzelany, 2020; Morrison, 2020). With the right business attitude, companies can turn COVID-19 challenges into business opportunities by using the on-going crisis to revamp their business process, train, retain and recruit key talents. Also, businesses should not shy away from trying new technologies, products and markets to meet customers and stakeholders demand. Remember, "When life gives you lemons, make lemonade". Be ready to face the next world.

\subsection{Stay Competitive through Stakeholder Loyalty and Trust}

Most businesses are concerned about the effect of COVID-19 on the relationship with their customers and other stakeholders. Companies should retain stakeholders' and customers' loyalty and trust by letting them know how valuable they are. These strategies include providing updates on business performance and offering incentives to frontline employees and customers. It is also essential for businesses to focus on internal strength, capabilities, and strategies to effectively handle the on-going challenges; thus, "Put your mask on before helping others."

\subsection{Reskill Organization with Human Capital Retention and Investment}

Most businesses had no choice rather than to force let go of some of its key employees due to cashflow constraints amid COVID-19. An article published by 
(Voytko, 2020) on May $27^{\text {th }}, 2020$, revealed that Boeing company has laid-off 67,700 of its work forces as a result of losing out to cashflow. On the other hand, companies in high demand and better financial positions such as CVS, Walmart, Instacart, Amazon, and Dollar General are recruiting talents and using the current market crisis as a competitive edge, (Alcorn, 2020). In the United States, over 26 million Americans have already lost their jobs to the coronavirus. Canada has so far reported over 1 million lost jobs (Bartash, 2020; Evans, 2020). Most of these workers affected are real talents from Silicon valley \& technology, the manufacturing, and logistics industry, airline industry, finance, and educational industry (Voytko, 2020). There is no other better opportunity time to recruit intellectual capitals than during these times. Businesses should be proactive by recruiting talents and use these downtimes to develop their existing pool of talent. Strategically, companies should also establish a formal program to anticipate and fulfill their talent needs (Cappelli, 2008).

\section{Practical and Research Implications}

\subsection{Practical Implications}

The study highlighted that the effective use of agility dimensions, artificial intelligence, and data analytics capabilities continues to be an excellent survival strategy for businesses during these times of COVID-19. To better leverage these technologies, managers within the supply chain network should use data aggregation and mining methods to gather historical and current data to help identify data patterns and relationships to make informed decisions.

Also, management should effectively apply agile business intelligence and predictive analytics capabilities to gain insight from data and information shared across an organization and its supply chain networks to help management identify, plan, and mitigate any risk in their business processes.

Furthermore, businesses should move from a reactive to a more proactive position by using supply chain artificial intelligence systems embedded with machine learning to provide predictive real-time insight into business opportunities, priorities, and challenges in meeting the demand of stakeholders.

Besides, the effective use of agile business intelligence will help managers ask and answer complex questions with the aid of natural language processing (NLP) in the quest to optimize their operations during this period.

Moreover, businesses should make effective use of agility business intelligence systems to better conduct cognitive analytics in their planning and response cycles to better produce essential and transformable products and services during and after the COVID-19 crisis.

The research further unearthed some administration strategies for managers and businesses on how to stay competitive amid the pandemic. Businesses must perceive the current on-going crisis as a wake-up call to revamp their business processes to better stay competitive. Businesses should also retain stakeholders' and customers' loyalty and trust by providing community support and incen- 
tives. Finally, businesses should re-skill their organization with human capital retention and investment.

\subsection{Research Implications and Limitations}

The novel COVID-19 has led to a wide range of research topics on supply chain management, education, healthcare, finance, tourism, and service delivery. This study contributes to the existing knowledge of Agile business intelligence and data analytics within the supply chain industry during these pandemic times. This study serves as a benchmark for future research on agile business intelligence and data analytics. Considerably, since this study is theoretical in nature, future studies should consider empirical studies to investigate agile business intelligence and data analytics capabilities, on business performance, especially during a public emergency crisis.

\section{Conclusion}

COVID-19 is already leading to a massive transformation in the business world, which requires adopting innovative ways of performing business activities across the service supply chain network, such as materials procurement, production, warehousing, inventory management, distribution/retail, and delivery.

During this period, the need for service supply chain integration through effective agility strategies, artificial intelligence, and data analytics to enable managers to make effective and resilient decisions within the various supply chain networks is crucial. Evidently, the five dimensions of agile risk management, the use of artificial intelligence systems, and data analytics will enable an organization and its service supply chain networks to access relevant information and data in real-time, find patterns in data, and identify uncertainties and opportunities, threats and make effective decisions.

This article serves as a practical guide for managers to make resilient and resolute decisions on strategy implementations, make changes to develop efficient and effective service supply chain strategies and business operations. By staying agile with artificial intelligence, data analytics, flexibility, and resilience, your business can survive as we fight COVID-19.

\section{Conflicts of Interest}

The authors declare no conflicts of interest regarding the publication of this paper.

\section{References}

Alcorn, C. (2020). These Companies Are Hiring Thousands of New Employees during the Coronavirus Pandemic. https://www.cnn.com/2020/03/23/business/coronavirus-companies-hiring/index.html

Baltacioglu, T., Ada, E., Kaplan, M. D., Yurt, O., \& Kaplan, Y. C. (2007). A New Framework for Service Supply Chains. Service Industries Journal, 27, 105-124. 
https://doi.org/10.1080/02642060601122629

Bartash, J. (2020). Jobless Claims Jump Another 4.4 Million-26 Million Americans Have Lost Their Jobs to the Coronavirus.

https://www.marketwatch.com/story/jobless-claims-jump-another-44-million-25-milli on-americans-have-lost-their-jobs-to-the-coronavirus-2020-04-23

BBC (2020). Coronavirus: iPhone Manufacturer Foxconn to Make Masks.

Blume Global (2020). How Artificial Intelligence Improves the Supply Chain. https://www.blumeglobal.com/learning/artificial-intelligence

Cappelli, P. (2008). Talent Management for the Twenty-First Century. Harvard Business Review, 86, 74-81.

de Smet, A. (2017). Untangling Your Organization's Decision Making. https://www.mckinsey.com/business-functions/organization/our-insights/untangling-y our-organizations-decision-making

Desai, D. (2020). COVID-19: How Canadian Restaurants Became Online Grocery Stores to Cater to Pandemic Demand.

https://www.theguardian.pe.ca/news/canada/covid-19-how-canadian-restaurants-beca me-online-grocery-stores-to-cater-to-pandemic-demand-438874

Ellram, L. M., Tate, W. L., \& Billington, C. (2004). Understanding and Managing the Services Supply Chain. Journal of Supply Chain Management, 40, 17-32.

https://doi.org/10.1111/j.1745-493X.2004.tb00176.x

Evans, P. (2020). Canada Lost More than 1 Million Jobs Last Month as COVID-19 Struck. https://www.cbc.ca/news/business/canada-jobs-march-covid-19-1.5527359

Fruhlinger, M. K. P. (2019). What Is Business Intelligence? Transforming Data into Business Insights.

https://www.cio.com/article/2439504/business-intelligence-definition-and-solutions.ht $\underline{\mathrm{ml}}$

Gorzelany, J. (2020). Car Sales and Service Providers Are Embracing Home Delivery Models in the Age of COVID-19.

https://www.forbes.com/sites/jimgorzelany/2020/03/24/car-sales-and-service-are-embr acing-home-delivery-models-in-the-age-of-covid-19/\#534f8771799f

Hudes, S. (2020). COVID-19: One-Third of Businesses Fear They'll Permanently Close within a Month.

https://calgaryherald.com/business/local-business/one-third-of-businesses-fear-covid-1 9-could-lead-to-permanent-closure-within-a-month

Imanuel. (2014). Top 13 Supply Chain Analytics Software. https://www.predictiveanalyticstoday.com/top-supply-chain-analytics-software

Meehan, L., \& Colette Seidel, M. (2019). Flat vs. Hierarchical Organizational Structure. Chron.com. Chron.

https://smallbusiness.chron.com/flat-vs-hierarchical-organizational-structure-724.html

Mich, D. (2020). Ford Works with 3M, GE, UAW to Speed Production of Respirators for Healthcare Workers, Ventilators for Coronavirus Patients.

Morrison, S. (2020). Ford and GM Are Making Tens of Thousands of Ventilators. It May Already Be Too Late.

https://www.vox.com/recode/2020/4/10/21209709/tesla-gm-ford-ventilators-coronavir $\underline{\text { us }}$

Pontius, N. (2020). Top Supply Chain Analytics: 50 Useful Software Solutions and Data Analysis Tools to Gain Valuable Supply Chain Insights. 
https://www.camcode.com/asset-tags/top-supply-chain-analytics

Trieu, R. (2020). 5 Ways Companies Are Pivoting Manufacturing to Help Fight COVID-19. https://www.autodesk.com/redshift/manufacturing-covid-19

Voytko, L. (2020). Coronavirus Layoffs: Lyft, Boeing Latest to Cut Workers amid Pandemic.

https://www.forbes.com/sites/lisettevoytko/2020/04/29/coronavirus-layoffs-boeing-cuts -10-of-workforce-amid-pandemic/\#7ebaf2863487

World Economic Forum (2020). This Is How Much the Coronavirus Will Cost the World's Economy, According to the UN.

https://www.weforum.org/agenda/2020/03/coronavirus-covid-19-cost-economy-2020un-trade-economics-pandemic 